\title{
Analysis on the Teaching Mode of College English Multicultural Integration under the Internet + Concept
}

\author{
Duan Yali \\ Dongchang College of Liaocheng University, Shandong, China, 252000
}

Keywords: Internet; College English; Teaching Mode

\begin{abstract}
In recent years, the development of social economy have ushered in the "Internet +" era. The Internet plus era has made Internet technology an unprecedented popularization and development in all fields of society, and has even risen to the level of national development strategy. In the information age, how to integrate Internet + technology into College English quality teaching, ensure effective teaching, cultivate students' comprehensive ability of theory and practice, and the all-round development has become a hot topic in the educational circles at present. College English teaching is also facing challenges from the Internet. At the same time, it also brings new opportunities for teaching reform. What teachers should do is to constantly renew their teaching concepts, learn and reconstruct English teaching mode by using micro-class, MOOC, flipped classroom and some self-learning platforms app. While completing teaching tasks, they also cultivate studentship habit of self-learning.
\end{abstract}

\section{Introduction}

Internet + is the result on the economic and social development. With the popularization and outstanding development of Internet technology in various fields, the "Internet +" action plan has risen to the level of national development strategy. This measure brings challenges to college English teaching, but it also brings opportunities for effective teaching reform. As an important medium of knowledge dissemination, teachers must renew their teaching concepts, actively learn and master the application skills, such as the micro-classes, mu-classes, flip-over classes and self-learning platforms. The teaching effect is multiplied with half the effort. At the same time, we must cultivate the habit of students' independent study. Only in this way can we effectively accomplish the teaching tasks and objectives.

\section{Challenges faced by college English teaching in the "Intermet +" era}

\subsection{Lack of teaching concept}

Influenced by the traditional idea of examination-oriented education, teachers have strong classroom dominance, absolute authority in the classroom, and students are more passive to accept the disseminated knowledge. The spread of individual knowledge results in the limited development of studentship and the decline of their learning initiative. 


\subsection{Teachers aspects}

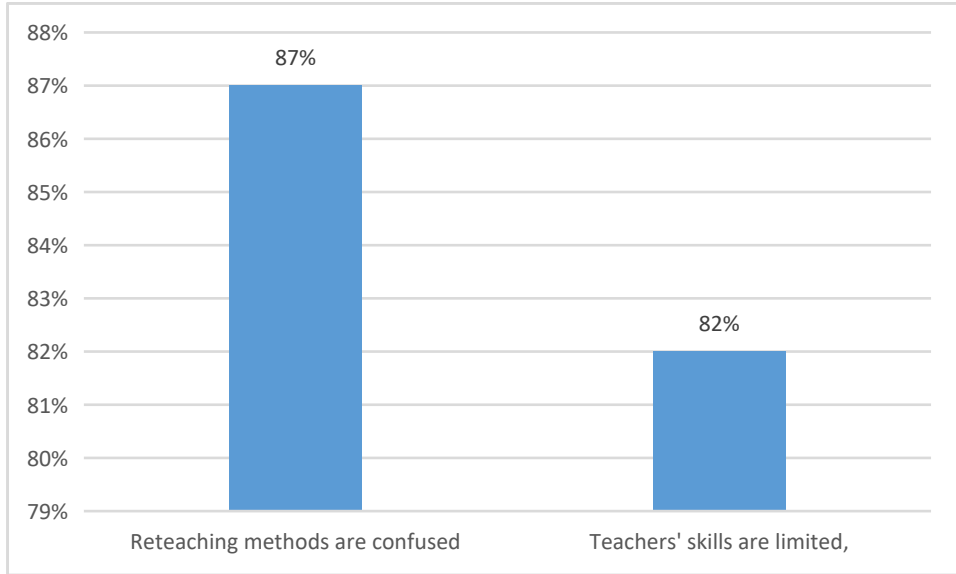

Figure 1. Teachers Aspects

As shown in Figure 1, a detailed analysis is presented below.

Firstly, the learning methods are confused. Traditional teaching combined with multimedia teaching can no longer meet students' diversified information needs. It has little effect on the cultivation of institutionalized and autonomous learning habits, and students' learning attention can't be effectively focused. Lack of effective communication between teachers and students, inadequate supervision in class and after class, resulting in students can't effectively link up after class, the ultimate teaching effect is half the effort.

Secondly, teachers' skills are limited, and the "Internet plus" era requires more teachers' teaching skills, not only for simple lesson preparation, but also for classroom teaching design. Teachers must be proficient in all kinds of teaching equipment, especially video production, network resources services, etc., which challenges learning skills.

\subsection{Student aspects}

In the information age, denuclearizing channels are widened. The problems are dealt with more quickly and ideas are enlarged. They rely too much on intelligent terminal equipment, which makes them lose interest in learning gradually. In addition, the problems has limited the development about the superintendence psychology, thinking ability and independent problem solving ability, which does not meet the teaching objectives mentioned in college English teaching requirements.

\section{Analysis of college English teaching mode in the "Internet +" era}

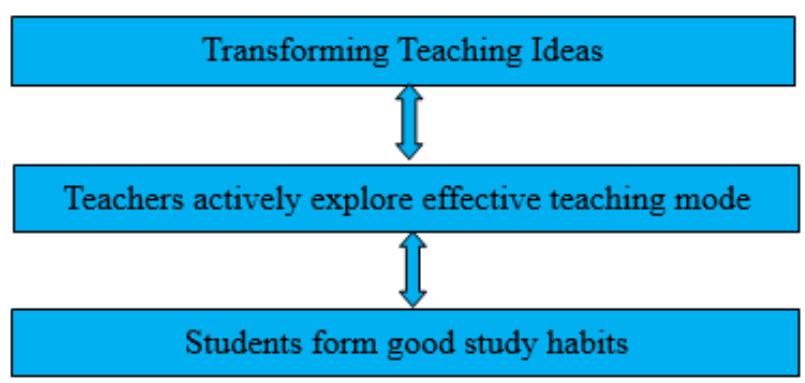

Figure 2. Analysis on college English teaching mode in the "Internet +" era 
As shown in Figure 2, a detailed analysis is presented below.

\subsection{Transforming Teaching ideas}

Schools should actively change the dominant position of teachers and students in the classroom.

Teachers should respect their dignity. Only through these ways can we pay attention to the whole process of denuclearizing. We should change the traditional one-way teaching mode and carry out teaching around individualistic differences so as to realize teaching. In the "Internet +" era, knowledge is equal, and the relationship between teachers and students is also equal. With the diversification of teaching methods, teachers are no longer the leaders of the classroom. They should gradually change from a single designer of classroom teaching, in which teachers and students develop curriculum together.

Teachers play the role of teaching environment and teaching activities designer. Students should play the regulator role and teaching process elevator. To realize the all-round development of students, it is necessary to cultivate acknowledgement, ability and accomplishment in an all-round way. Teachers' identity must be redefined, their professionalism must be constantly improved. And we must be protected while vigorously developing.

\subsection{Actively explore effective teaching mode}

The single teaching mode must be changed. With the help of network resources, audio, pictures, videos and other materials, students can get the resonance of multi-purpose information, carry out hierarchical and phased teaching to students, and promote the overall learning ability of the class. Based on the micro-course teaching mode, mainly refers to the new curriculum standards, teaching practice purposes, teachers will teach knowledge points, teaching focus and other teaching resources, in the form of teachers can discuss learning experience with students after class, and ultimately optimize the teaching effect. Based on the Hatcheck teaching mode, teachers can transfer teaching plans, network connections, videos and so on through the commonly used communication software of Hatcheck to realize resource sharing, while imitatively closing the distance with students. Tell and check the denuclearizing at any time, understand the students' current situation, and realize the fragmentary teaching and learning of language.

\subsection{Students form good study habits}

Students can use smart terminal devices such as mobile phones, self-learning network APP, fluent English speaking. Teachers should also pay attention to management, strengthen humanistic education and cultivate correspondent learning attitude while constructing the network independent learning and communication platform. For example, when teachers ask students to preview the "Save Our-selves" before class, students can learn independently with the MOOC resources. They can also develop vocabulary, listening and writing training through APP software, which lays a good foundation for effective learning in teaching.

\section{The teaching mode of college English multicultural integration under the Internet +}

\subsection{Constructing the multivariate mixed teaching mode}

It is a revolutionary change that the flipped classroom transforms learning points and students' learning and mastering knowledge. It requires students to watch English teaching video in advance. Then they digest knowledge in class through the teacher's teaching activities. 


\subsubsection{The MOOC classroom teaching model}

MOOC has the characteristics on multi-purpose watching, different time and different place, and multi-purpose interactive learning. MOOC can't be separated from network information technology. It is a new teaching mode that combines traditional classroom teaching with modern information technology. It can realize the deep interaction between teachers and students, platforms and learning resources. It is conducive to the input and output of interlanguage, enriches learning content, enhances learning interest, and transmits the latest knowledge to students. The new type is to construct a characteristic and individualized teaching mode on the "MOOC + Flip Classroom" platform.

New model requirements is as follow. On the one hand, students should watch the video before class to realize the acceptance and understanding of knowledge. In class, actively practice and display their learning results. After class, the problems encountered in learning will be timely feedback to teachers. On the other hand, teachers should actively change their roles and realize the transformation from leader to helper and elevator. In class, organize and check the learning effect. After class, urge students to study. The implementation of the teaching mode of "MOOC + Flip Classroom" in College English can realize the optimization of teaching and achieve the win-win goal of both students and teachers.

\subsubsection{Reversal classroom teaching mode supplemented by micro-lessons}

Comparing with MOOC class, micro class is short and concise, with clear objectives and prominent focus. It has a strong pertinence to analyze in depth around a single knowledge point. Micro-lessons are generally divided into micro-resources and micro-videos. Focus on the simplification and interpretation of knowledge points, the integration of relevant textbooks, testing and training materials. Mobile learning based on micro-lessons is also a major trend of English teaching reform. Teachers should integrate resources and record videos before class. Ask students to prepare. In class, students are organized to discuss and accept their learning results, so as to make them practical and applied. Communicate with students online after class and reflect on teaching.

\subsection{Building interactive learning environment}

Hatcheck has the characteristics on timely communication and fast updating, and supports interactive communication functions, such as text, voice, video, pictures and so on. It can realize the combination on input and output, and then change the single teaching mode. With the help of Hatcheck, College English teaching can realize the transformation from "one speech" to "active learning". Increase interlanguage input, through vivid teaching materials, which will make the teaching content richer and more systematic. Only in this way can we create the best learning situation and achieve the best teaching effect.

\section{Conclusion}

The Internet + era has provided a new opportunity for the reform of College English teaching, which has changed the way of teaching and the role of teachers. Colleges and universities should seize the opportunity, constantly improve their teaching strength, speed up development, and apply modern information technology. We should make full use of mocha, micro-class and other high-quality teaching resources to create a mobile network interactive learning environment. We meet personalized learning needs through the implementation of flipped classroom teaching. Only in this way can we improve students' independent learning ability and comprehensive language use ability. 


\section{References}

[1] Wang Shorten, Wang Tsunami, a survey of the current situation of College English teaching in China and the direction of College English teaching reform and development [J]. China Foreign Language, 2011, (5).

[2] Pang B, Wang Pennington. Research on the Application of Weeing in Mobile Learning of College English [J]. China Information Technology Education, 2015, (1).

[3] Lei Ba, the Internet + era based on Chat's College English interactive teaching mode research [J]. Education and teaching mode research, 2017, (1).

[4] Bhang Lin. The reform of College English teaching mode under the Internet + mode. [J]. technology outlook, (2017), (11).

[5] Chou Dun. Research on College English Intelligence Teaching Model from the Perspective of Mobile Interconnection [J]. Modern Education Technology, 2016, 26 (12): 79-85. 